\title{
Servant leadership and employee voice: a moderated mediation
}

\author{
Yang Song \\ Shanghai University of Finance and Economics, Shanghai, China \\ Qi-tao Tian \\ Henan University of Economics and Law, Zhengzhou, China, and \\ Ho Kwong Kwan \\ Organizational Behavior and Human Resource Management Department, \\ China Europe International Business School, Shanghai, China
}

\begin{abstract}
Purpose - The purpose of this paper is to examine the effects of servant leadership on employees' promotive voice behavior and prohibitive voice behavior by focusing on the mediating role of job engagement and the moderating role of proactive personality.

Design/methodology/approach - Time-lagged data were collected using a field survey research design. The participants included 216 employees and 23 supervisors in two commercial banks in China.

Findings - Perceived servant leadership was positively related to employees' promotive and prohibitive voice behavior, and these relationships were mediated by enhanced job engagement. In addition, employees' proactive personality amplified the relationship between perceived servant leadership and job engagement, and the mediating effect of job engagement on the relationship between perceived servant leadership and voice behavior.

Research limitations/implications - This study enhances understanding of the mechanisms underlying the servant leadership - voice model by identifying the mediating role of job engagement. The results also demonstrate the moderating role of proactive personality in enhancing the effects of servant leadership. However, the survey design was not longitudinal, which limits the study's ability to confirm causality.

Practical implications - The findings reveal that servant leadership, employees' job engagement, and proactive personality can facilitate employees' promotive and prohibitive voice behavior.

Originality/value - This study addresses the unexplored mediating mechanism of the relationship between servant leadership and voice behavior, and offers new directions for servant leadership and voice research.

Keywords Servant leadership, Job engagement, Promotive voice, Prohibitive voice, Proactive personality

Paper type Research paper
\end{abstract}

As organizations become increasingly reliant on their employees' knowledge and ideas in today's competitive and uncertain environment (Duan et al., 2014), promoting employee voice has become a vital issue. Employee voice has two dimensions: promotive and prohibitive. Promotive voice is when one vocalizes ways to benefit the organization, and prohibitive voice is when one vocalizes deficiencies or potential threats in the organization (Liang et al., 2012). Both are critical to organizational effectiveness and even to business survival because they

(C) Yang Song, Qi-tao Tian and Ho Kwong Kwan. Published by Emerald Publishing Limited. This article is published under the Creative Commons Attribution (CC BY 4.0) licence. Anyone may reproduce, distribute, translate and create derivative works of this article (for both commercial and non-commercial purposes), subject to full attribution to the original publication and authors. The full terms of this licence may be seen at http://creativecommons.org/licences/by/4.0/legalcode

This study was funded by the National Natural Science Foundation of China (Grant No. 71672108), the Social Science Foundation of Henan Province, China (Grant No. 2020-ZZJH-033), NG Teng Fong/ Sino Outstanding Youth Fund of HUEL, and China Europe International Business School (Grant Nos 19TEOMA and AG21TEO).

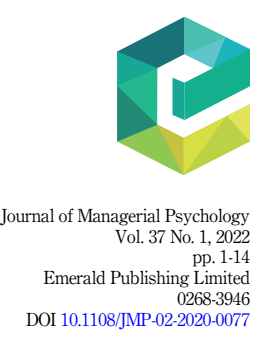

Received 16 February 2020 Revised 10 October 2020 24 February 2021 10 May 2021 Accepted 24 May 2021 
JMP

37,1

2

are conducive to decision-making, innovation, and improvements to the work process, correcting problems and preventing crises (Liang et al., 2012; Morrison, 2011). However, there is a lack of research exploring antecedents that elicit these two forms of voice in a single model (Chamberlin et al., 2017). This issue is particularly important and timely in the Chinese context (Duan et al., 2014; Yan and Xiao, 2016), as China is transforming from a centrally planned economy to a market economy, and its social and legal economic systems are undergoing tremendous change.

In a context in which employees' voices and intelligence are deemed critical, the efficacy of traditional management styles that simply seek subordinates' compliance with standards and rules has been challenged (Duan et al., 2014). To inspire employees to contribute their insights and ideas, people-oriented leadership styles are needed to facilitate employees' knowledge and abilities. Servant leadership is the most people-oriented leadership style. Its specific purpose is to fulfill employee needs to grow, develop, and prosper (Greenleaf, 1977). Previous studies have documented a positive relationship between servant leadership and employee voice (e.g., Arain et al., 2019; Duan et al., 2014; Yan and Xiao, 2016). However, these studies have mainly relied on the social exchange process to explain why servant leaders promote pro-organizational behavior (e.g., Saks, 2006; Yan and Xiao, 2016), failing to tap the selfless essence of servant leadership. Rather than following reciprocity rules, servant leaders offer unconditional services to help employees improve, as their priority is employee growth (Hoch et al., 2018).

This priority coincides with employees' own desire for a better self - this internal motivation leads employees to engage in various positive work behaviors. We, therefore, view the relationship between servant leadership and employee voice through a selfenhancement lens, and suggest that employees are motivated to display more job engagement and to express promotive and prohibitive voice by a desire to maintain a positive self-view. Job engagement refers to employees' simultaneous investment of physical, emotional and cognitive energies in their work roles (Kahn, 1990; Rich et al., 2010). Such job engagement enhances employees' ability to generate ideas and discover deficiencies because of the continuous involvement and effort employees devote to their work. According to selfenhancement theory, individuals desire to view themselves and be viewed by others in a positive light (Ferris et al., 2015; Pfeffer and Fong, 2005). Voice behavior can be seen as a means of self-enhancement because the efficacious voice is associated with competence and influence (Wei et al., 2015). We argue that servant leadership can offer a range of selfenhancement incentives and conditions that drive employees to invest more time and energy in the work domain and to engage in voice behavior.

This process may be affected by employees' personality traits. The person-supervisor fit perspective suggests that employees generate better work outcomes when their characteristics and their supervisor's characteristics or leadership style are well matched (Kristof-Brown et al., 2005). We contend that employees' proactive personality - defined as a behavioral tendency to identify opportunities to enact change, show initiative, and act (Bateman and Crant, 1993) - may interact with servant leadership to influence employee's job engagement and voice behavior. Previous studies of the above interactive effect have reached inconsistent conclusions regarding whether employees' proactive personality enhances or impairs the servant leadership effect (e.g., Newman et al., 2017; Panaccio et al., 2015). This inconsistency drives us to examine the subject again using Chinese data to determine the moderating role of proactive personality on the effect of servant leadership.

This study makes three main contributions. First, it offers a self-enhancement view and identifies servant leadership and job engagement as factors that enhance promotive voice and prohibitive voice among employees. This new perspective emphasizes servant leadership's role in facilitating employees' self-enhancement, which enriches current theoretical frameworks. Second, it tests the moderating role of proactive personality, 
thereby providing insight into when the positive effect of servant leadership is enhanced. Third, employee voice has mainly been studied in Western countries; we use Chinese samples to examine the generalizability of the voice models in a context in which social and cultural factors may discourage voice (Huang et al., 2005).

\section{Hypothesis development}

Servant leadership, job engagement and employee voice

Self-enhancement theory demonstrates the simple but robust principle that individuals tend to seek to maintain a positive sense of self (Chen et al., 2013; Pfeffer and Fong, 2005). The extent to which individuals invest their sense of self in work is represented in the process of engagement (Kahn, 1990). To maintain a positive sense of self, individuals tend to invest more time and energy in domains in which their self-worth is enhanced and reduce such investment in domains in which their self-worth is threatened (Chen et al., 2013; Crocker et al., 2003). This theory helps to illustrate why employees display work engagement and why they may disengage from work. We argue that servant leadership creates a favorable environment in which employees' self-worth is enhanced. That is, employees are more likely to be engaged in their work when they are provided with sufficient opportunities for self-enhancement by servant leaders.

Kahn (1990) illustrated three psychological conditions - meaningfulness, safety, and availability - that affect personal engagement and disengagement. We argue that employees use these conditions to measure whether the environment is conducive to self-enhancement. Meaningfulness is engendered when individuals feel valued, worthwhile, and useful in their work (Kahn, 1990). Servant leaders see each employee as a unique individual who deserves to be valued and consider each employee's opinion when making important decisions (Ehrhart, 2004; Van Dierendonck, 2011). Their actions lead subordinates to believe that they are respected at work and are valuable to the organization. Therefore, employees with servant leaders are more likely to engender work engagement as these feelings allow employees to maintain a positive self-view.

Safety can be defined as a social environment that is trustworthy, nonthreatening, and predictable (Kahn, 1990). Servant leaders create a safe environment in which employees feel trusted, accepted and free to make mistakes (Van Dierendonck, 2011), because such leaders encourage employees to make work decisions and handle difficult situations independently (Ehrhart, 2004; Liden et al., 2008). Therefore, perceived servant leadership facilitates work engagement by fostering psychologically safe working conditions in which one's self-image will not be damaged.

Finally, availability is associated with having sufficient physical, emotional and psychological resources to engage in role performance (Kahn, 1990). Employees are available to commit themselves fully to their roles when they can cope with various work and personal demands. Servant leaders meet their followers' work and personal growth needs by engaging in one-to-one communication with followers and creating customized services to support their followers' career goals (Greenleaf, 1977). Therefore, employees can easily obtain critical information and assistance from servant leaders to support their individual needs and further job engagement.

In sum, self-enhancement theory proposes that individuals form their self-worth based on how they are treated by others (Ferris et al., 2015; Pfeffer and Fong, 2005). As leaders play a key role in representing an organization, perceptions of servant leadership enhance employees' self-worth within the organization and subsequent job engagement. We, therefore, propose the following hypothesis.

H1. The perception of servant leadership is positively related to employees' job engagement. 
JMP 37,1

Self-enhancement theory further suggests that individuals seek to self-enhance and excel in domains to which their sense of self is tied (Ferris et al., 2015). Because engaged employees have deeply invested their sense of self in their work, they are more motivated to show superior competence and positive image at work than disengaged individuals (Chen et al., 2013). We argue that expressing promotive and prohibitive voice is a way for engaged employees to demonstrate their excellence and outstanding value by exhibiting their insightful and creative views. Voice behavior is, therefore, the result of self-enhancement.

Expressing promotive voice is easily associated with one's knowledgeable and thoughtful image and enhances others' positive views of the voice contributor. Job engagement is helpful in generating promotive voice. Because fully engaged employees invest all of their physical, emotional and cognitive effort in work (Kahn, 1990), their continuous cognitive effort and attentiveness to organizational issues enable them to generate creative ideas and suggestions that improve the organizational status quo. Further, fully engaged employees are more likely to go beyond their job description (Rich et al., 2010), enabling them to learn and identify ways to improve.

Expressing prohibitive voice demonstrates personal value and enhances an employee's professional image, because directly pointing out organizational dysfunctions signifies the speaker's responsible and straightforward character. However, prohibitive voice involves more risks than promotive voice as revealing harmful practices, incidents or behaviors in an organization may displease the implicated personnel (Liang et al., 2012). We argue that job engagement can facilitate prohibitive voice by diminishing employees' fears and concerns about expressing their opinions. Engaged workers who are dedicated to and immersed in work are less likely to stop and evaluate the favorability of the social context for prohibitive voice (Schaufeli et al., 2002); when they detect a problem during work, their instinct is to speak up immediately. In addition, when employees are absorbed in and focused on work, they are more likely to discover deficiencies in and potential threats to their organization (Sonnentag, 2003). We thus propose the following hypothesis.

H2. Job engagement is positively related to (a) promotive voice and (b) prohibitive voice.

As a motivational construct, job engagement has been found to be an effective mediator linking organizational factors to employee behavior based on self-enhancement theory (Chen et al., 2013). This theory explains why employees engage in voice behavior as a means of selfenhancement, and how servant leadership facilitates this process by providing selfenhancement incentives to job engagement. Drawing on self-enhancement theory, we argue that employees can be driven to engage in voice behavior through the continuous investment of their selves in their work role, and that this process is enabled by servant leaders. Specifically, servant leadership can create the three aforementioned psychological conditions that improve employee engagement. Accordingly, the physical, emotional and cognitive efforts that employees invest in work not only help them to identify and freely express prohibitive voice but also generate creative ideas for promotive voice. Hence, we propose the following hypothesis.

H3. Job engagement mediates the relationships between servant leadership and (a) promotive voice and (b) prohibitive voice.

\section{The moderating role of proactive personality}

Kahn (1990) suggested that differences in personality traits are likely to shape employees' tendency to engage at work. A meta-analysis further found consistent evidence that proactive individuals who tend to interact with their environment are more likely to become engaged in their jobs (Christian et al., 2011). We thus expect employees with proactive personalities to fully use their servant leader's assistance to accomplish tasks and become innovative at 
solving problems and raising new ideas. Proactive individuals are also more likely than passive individuals to recognize the resources that servant leaders can provide because proactive individuals seek opportunities for change (Bateman and Crant, 1993). Further, proactive employees tend to proactively invest the resources provided in their work roles and persist in their tasks because they demonstrate initiative and perseverance (Crant, 1995). In short, employees' attitudes toward opportunities determine how they perceive and use the resources received from servant leaders.

From the servant leaders' perspective, their individualized consideration actions (e.g., oneto-one communication with followers) allow them to quickly sense when employees show a need for growth and then provide tailored skills and resources to employees in a timely fashion (Liden et al., 2008). Proactive employees may thus receive better service because they tend to proactively look for support from their leaders, whereas passive employees do not clearly express their needs. As a result, proactive employees are more likely to acquire benefits from servant leaders and achieve the psychological conditions that promote job engagement.

We argue that proactive employees and servant leaders are well matched to generate maximum benefits for individual development, which is in line with the person-supervisor fit perspective (Kristof-Brown et al., 2005). Because servant leaders' primary focus is on their followers' development (Hoch et al., 2018), they can promptly meet the needs of proactive employees, rather than treating them as a lower priority. Proactive employees can therefore obtain valuable information and techniques that help them achieve their career goals from servant leaders, rather than merely general support and coaching that aims to benefit the organization. Hence, we propose the following hypothesis.

H4. Proactive personality moderates the relationship between servant leadership and job engagement, such that the relationship is stronger when the level of proactive personality is high rather than low.

The foregoing arguments explain the mediating role of job engagement in the effect of servant leadership on promotive and prohibitive voice behavior. In addition, they illustrate the enhancing effect of proactive personality on the servant leadership-job engagement relationship. Combining these two effects, we propose that proactive personality intensifies the mediating effect of job engagement on the relationships among servant leadership, promotive voice, and prohibitive voice, which can be represented by a moderated mediation model (Edwards and Lambert, 2007). Employees who have a higher degree of proactive personality are more likely to obtain the opportunities to maintain self-worth arising from servant leadership and to exhibit more work engagement and voice behavior. Accordingly, the indirect effect of servant leadership on promotive and prohibitive voice behavior should be stronger. We therefore propose the following hypothesis.

H5. Proactive personality moderates the mediating effect of job engagement on the relationships between servant leadership and (a) promotive voice and (b) prohibitive voice, such that the mediating effect is stronger when the level of proactive personality is high rather than low.

\section{Methods}

\section{Sample and procedures}

Our sample consisted of 23 supervisors matched with 263 subordinates who worked in two commercial banks in China. Three waves and two sources of surveys were administered to avoid the common method variance problem. In the first wave, the subordinates were invited to fill out questionnaires about their supervisors' servant leadership, their own proactive 
JMP

37,1

6

personality, their organizational tenure, and other demographic information. One week later, they were asked to rate their job engagement over the past week. During the third week, 23 supervisors of the subordinates surveyed in both waves were invited to evaluate the subordinates' promotive and prohibitive voice behavior. We explained the research purpose and scope to all of the participants to ensure that their participation was voluntary. Finally, we collected 216 completed questionnaires from the subordinates, giving a response rate of $82.1 \%$. All 23 supervisors completed their ratings of the subordinates. The final sample consisted of 216 supervisor-subordinate dyads.

The subordinates' average age was $31.4(\mathrm{SD}=7.98)$ years, and the average organizational tenure was 8.75 years $(\mathrm{SD}=7.66)$. The majority were women $(135,62.50 \%)$. With respect to the highest educational level attained, $164(75.93 \%)$ subordinates had achieved a bachelor's degree, $24(11.11 \%)$ had an associate's degree, $22(10.19 \%)$ had a postgraduate degree, and 6 $(2.78 \%)$ had a high school diploma or below. In contrast to the subordinate sample, most of the supervisors were men $(15,65.22 \%)$. Their average age was $42.43(\mathrm{SD}=4.88)$ and their average organizational tenure was $20.48(\mathrm{SD}=5.10)$ years. All of the supervisors had a bachelor's degree and one held a postgraduate degree.

\section{Measures}

The response scales for all of the measures were based on a five-point agreement scale where 1 represented "strongly disagree" and 5 represented "strongly agree." All of the main measurements in this study were developed in Western countries in English. Therefore, the questionnaire surveys involving the key variables were translated and back-translated into Chinese in line with established cross-cultural translation procedures (Brislin, 1980).

Perceived servant leadership behavior. To assess the subordinates' perceived servant leadership, we used the 14-item measure developed by Ehrhart (2004). A sample item is "my supervisor spends the time to form a quality relationship with department employees." The scale's reliability was 0.97 .

Proactive personality. We measured proactive personality using the adjusted four items developed by Parker et al. (2006) from Bateman and Crant's (1993) 17-item scale. A sample item is "I am excellent at identifying opportunity." The scale's reliability was 0.76 .

Job engagement. The 18-item scale developed by Rich et al. (2010) was adopted to measure the subordinates' job engagement. A sample item is "at work, my mind is focused on my job." The scale's reliability was 0.97 .

Voice behavior. Liang et al. (2012) divided voice behavior into promotive voice and prohibitive voice, then developed five items to assess each (ten items in all). We used these items to measure the subordinates' promotive and prohibitive voices. A sample item for promotive voice behavior is "proactively suggest new projects that are beneficial to the work team." A sample item for prohibitive voice behavior is "speak up honestly with problems that might cause serious loss to the work unit, even when/though dissenting opinions exist." Direct supervisors rated both types of employee voice. The scale's reliability for promotive voice and prohibitive voice was 0.95 and 0.94 , respectively.

Control variables. Consistent with previous studies (Gao and Jiang, 2019; Takeuchi et al., 2012), both supervisors' and subordinates' gender, age, education, and organizational tenure were controlled to consider the potential impact of demographic factors on employees' decisions to voice their thoughts. Gender was classified into two groups $(1=$ female, $2=$ male). Educational level was measured by four categories: high school diploma or below, associate's degree, bachelor's degree, and postgraduate's degree. Age and organizational tenure were measured in years.

We also controlled for transformational leadership and employees' psychological safety. Research has provided evidence that transformational leadership is positively related to 
organizational citizenship behaviors and proactive behaviors in general (e.g., Podsakoff $e$ t al., 1990), and that psychological safety is an important psychological antecedent of promotive voice and prohibitive voice (Liang et al., 2012). We measured transformational leadership using the 11-item scale developed by Sparks and Schenk (2001). A sample item is "my supervisor leads by example." The scale's reliability was 0.97 . Psychological safety was assessed using five items adapted by Liang et al. (2012) from previous research (Brown and Leigh, 1996). A sample item is "in my work unit, I can freely express my thoughts." The scale's reliability was 0.76 .

\section{Results \\ Confirmatory factor analyses}

Confirmatory factor analysis (CFA) was conducted to examine the convergent and discriminant validity of the constructs. We first parceled the scales with more than ten items using a random assignment technique (Matsunaga, 2008) to create seven parcels for the 14-item servant leadership (SL) scale, six parcels for the 11-item transformational leadership (TL) scale, and nine parcels for the 18-item job engagement (JE) scale. After item parceling, the proposed 7-factor model, including SL, TL, JE, psychological safety (PS), proactive personality (PP), promotive voice (PV1), and prohibitive voice (PV2), provided a good fit to the data $\left(\chi^{2}=1170.44, \mathrm{df}=749, \mathrm{CFI}=0.91, \mathrm{TLI}=0.90, \mathrm{RMSEA}=0.07\right.$, and SRMR $\left.=0.07\right)$. This model achieved a significantly better fit than the 6 -factor model that combined SL and $\mathrm{TL}\left(\Delta \chi^{2}(6)=93.32, p<0.01\right), \mathrm{PV} 1$ and PV2 $\left(\Delta \chi^{2}(6)=225.53, p<0.01\right)$ and the 5-factor model that combined PP, PS, and JE $\left(\Delta \chi^{2}(11)=489.71, p<0.01\right)$, indicating its discriminant validity.

\section{Descriptive statistics}

The means, standard deviations, bivariate correlations, and reliabilities of the variables are reported in Table 1 . We also calculated variance inflation factors (VIFs) to examine the multicollinearity of the independent variables. The VIFs were all below 10 (3.77 for servant leadership, 3.69 for transformational leadership), suggesting that no serious multicollinearity existed in the regression model (Hair et al., 2010).

\section{Test of the hypotheses}

Mplus 6.12 was used to conduct the multilevel structural equation modeling that allowed us to control the subordinate (level 1) and supervisor (level 2) variables (gender, age, education, and organizational tenure) at the same time. The model results are displayed in Table 2.

As shown in Table 2, servant leadership was positively associated with employees' job engagement $(\beta=0.26, p<0.01)$ when transformational leadership was controlled. Therefore, H1 was supported.

Job engagement was positively related to employees' promotive voice $(\beta=0.17, p<0.01)$ and prohibitive voice $(\beta=0.15, p<0.01)$ when we further controlled for psychological safety, supporting $\mathrm{H} 2$.

We then used bootstrapping analyses to test the mediating effects of job engagement as predicted by H3. The results indicated that servant leadership indirectly affected both types of voice through job engagement, with an indirect effect $=0.04(95 \% \mathrm{CI}: 0.01,0.08)$ on promotive voice and an indirect effect $=0.04$ (95\% CI: $0.01,0.07)$ on prohibitive voice. Therefore, H3 was supported.

We used the moderated causal step approach (Muller et al., 2005) to test H4, which predicted that proactive personality amplified the impact of servant leadership on job engagement. The data for servant leadership and job engagement were mean-centered. The results showed that the interaction effect was significant $(\beta=0.16, p<0.01)$. We adopted 
JMP

8

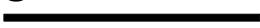

Table 1.

Means, standard deviations, bivariate correlations, and reliabilities of variables

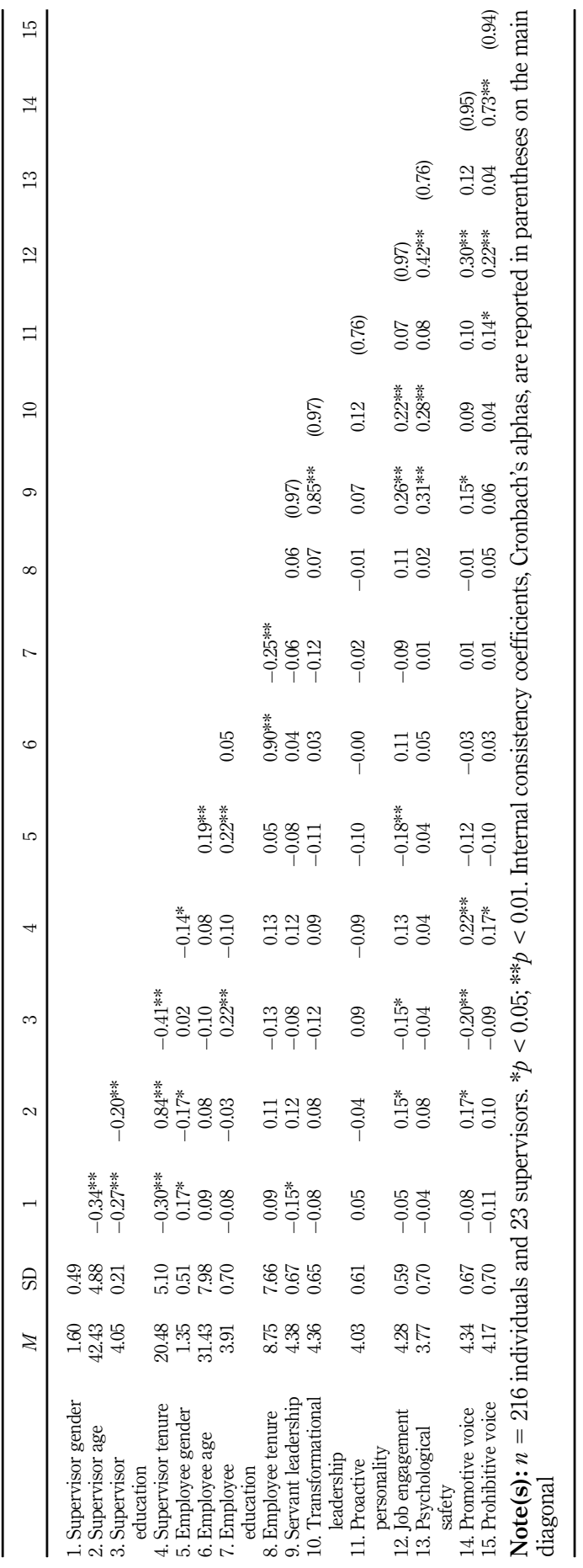




\begin{tabular}{|c|c|c|c|c|c|c|c|}
\hline & \multicolumn{2}{|c|}{$\begin{array}{l}\text { Mediator model } \\
\text { Job engagement }\end{array}$} & \multicolumn{4}{|c|}{ Dependent variable model } & \multirow{2}{*}{$\begin{array}{r}\text { Servant } \\
\text { leadership and } \\
\text { employee voice }\end{array}$} \\
\hline & $\begin{array}{l}\text { Job enga } \\
\text { Coeff. }\end{array}$ & & $\begin{array}{l}\text { Promoti } \\
\text { Coeff. }\end{array}$ & $\begin{array}{l}\text { voice } \\
\text { S.E. }\end{array}$ & $\begin{array}{l}\text { Prohibiti } \\
\text { Coeff. }\end{array}$ & $\begin{array}{c}\text { voice } \\
\text { S.E. }\end{array}$ & \\
\hline \multicolumn{8}{|l|}{ Control variables } \\
\hline Employee gender & $-0.28^{*}$ & 0.12 & -0.05 & 0.07 & -0.08 & 0.11 & \multirow{10}{*}{9} \\
\hline Employee age & 0.03 & 0.02 & -0.02 & 0.01 & -0.01 & 0.02 & \\
\hline Employee education & -0.10 & 0.12 & 0.15 & 0.08 & 0.12 & 0.08 & \\
\hline Employee tenure & -0.02 & 0.02 & 0.01 & 0.01 & 0.02 & 0.02 & \\
\hline Supervisor gender & -0.04 & 0.19 & -0.08 & 0.12 & -0.13 & 0.13 & \\
\hline Supervisor age & 0.02 & 0.02 & -0.00 & 0.02 & -0.03 & 0.02 & \\
\hline Supervisor education & -0.46 & 0.36 & -0.58 & 0.35 & -0.14 & 0.35 & \\
\hline Supervisor tenure & -0.01 & 0.03 & 0.02 & 0.03 & 0.04 & 0.03 & \\
\hline Psychological safety & & & 0.00 & 0.08 & -0.04 & 0.11 & \\
\hline Transformational leadership & -0.05 & 0.17 & -0.06 & 0.12 & -0.06 & 0.12 & \\
\hline \multicolumn{8}{|l|}{ Independent variable } \\
\hline Servant leadership & $0.26^{* * *}$ & 0.09 & 0.04 & 0.09 & -0.00 & 0.10 & \\
\hline \multicolumn{8}{|l|}{ Moderator } \\
\hline Proactive personality & 0.07 & 0.06 & & & & & \\
\hline \multicolumn{8}{|l|}{ Interaction } \\
\hline Servant leadership $\times$ Proactive personality & $0.16^{* *}$ & 0.05 & & & & & \\
\hline \multirow{2}{*}{\multicolumn{3}{|c|}{$\begin{array}{l}\text { Mediator } \\
\text { Job engagement }\end{array}$}} & & & & & \\
\hline & & & $0.17^{* * *}$ & 0.06 & $0.15^{* *}$ & 0.06 & Results of structural \\
\hline \multicolumn{8}{|c|}{ Note(s): $n=216$ individuals and 23 supervisors. $* p<0.05 ; * * p<0.01$} \\
\hline
\end{tabular}

Stone and Hollenbeck's (1989) procedure to plot the interaction effect to better interpret the results (Figure 1). The slopes were calculated at high $(+1 \mathrm{SD})$ and low $(-1 \mathrm{SD})$ levels of proactive personality. Figure 1 demonstrates that servant leadership was more positively associated with the subordinate employees' job engagement when they had a high level of proactive personality $(\beta=0.42, p<0.01)$ rather than a low level $(\beta=0.10$, n.s.). Therefore, $\mathrm{H} 4$ was supported.

To test H5, we computed the indirect effects of servant leadership on promotive and prohibitive voice through job engagement with low and high levels of proactive personality (Edwards and Lambert, 2007). The indirect effects were both significant $(\beta=0.07, p<0.01$; $\beta=0.06, p<0.01$ ) when the subordinate employees had a high level of proactive personality. However, the indirect effects were not significant ( $\beta=0.02$, n.s.; $\beta=0.01$, n.s.) when they had a low level of proactive personality. The differences in the indirect effects were both significant $(\beta=0.05, p<0.05 ; \beta=0.05, p<0.05)$, supporting H5.

\section{Discussion}

The proposed relationships among servant leadership, job engagement, promotive voice, prohibitive voice, and proactive personality were all supported by this study using timelagged dyadic data from two Chinese banks. The results indicated that job engagement mediated the effects of servant leadership on promotive voice behavior and prohibitive voice behavior. Further, a high level of proactive personality among employees amplified the positive relationship between servant leadership and job engagement. Proactive personality also moderated the mediating effect of job engagement on the servant leadership-voice relationship such that the mediating effect was only significant when employees had high levels of proactive personality. These results contribute to our understanding of employee voice in several ways. 
JMP

10

Figure 1.

The interactive effect of servant leadership and proactive personality on job engagement

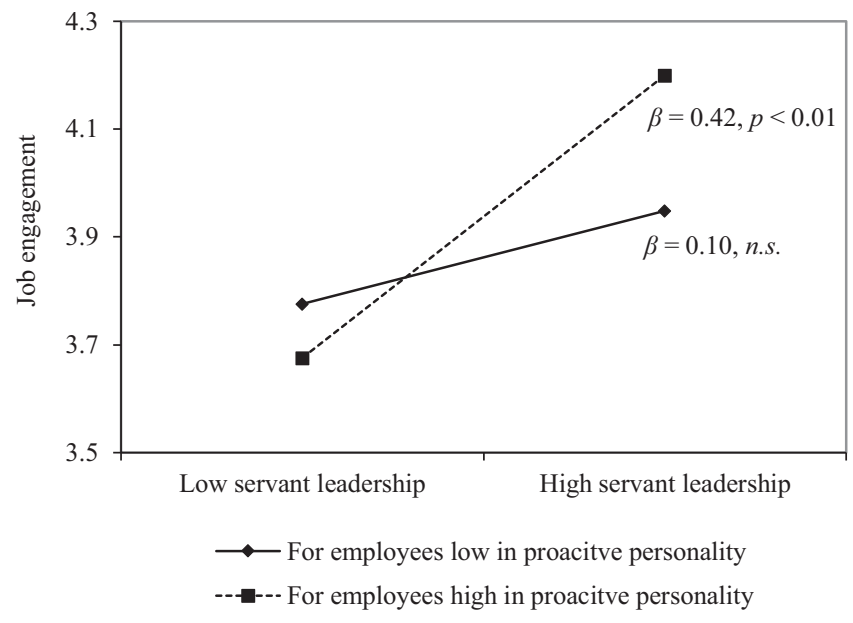

Theoretical contributions

First, this study empirically examined the impact of servant leadership on the two forms of voice (promotive and prohibitive), thereby providing a greater understanding of both. Most previous studies have either failed to distinguish between the two forms of voice (e.g., Duan et al., 2014; Yan and Xiao, 2016) or distinguished between them but failed to affirm the effect of servant leadership on both forms (e.g., Arain et al., 2019). Confirming the positive impact of servant leadership on both forms of voice is therefore an important contribution. We show that servant leadership facilitates both types of voice, and the results are significant beyond the effects of transformational leadership. This study thus answers the call to investigate leadership styles that are conducive to employee voice in Asia (Lam et al., 2012).

Second, this study offers a novel perspective on the association between servant leadership and employee voice by identifying job engagement as a mediator using the selfenhancement perspective. The self-enhancement theory provides an alternative explanation for the effect of servant leadership beyond social exchange theory - a key theoretical framework in servant leadership research that posits a reciprocal relationship between leader treatments and employee behavior (Sendjaya and Sarros, 2002). Our model, however, emphasizes the selfless nature of servant leaders in their interactions with followers, and reveals that servant leadership promotes employee voice by enhancing employees' self-worth and desire for excellence. This study therefore contributes to the voice literature by suggesting the self-enhancement motivation for employees' voice behavior.

Third, this study provides evidence that an employee's proactive personality strengthens the positive impact of servant leadership on job engagement, promotive voice, and prohibitive voice. Previous studies have explored the moderating role of proactive personality on the effect of servant leadership from different theoretical perspectives. Panaccio et al. (2015), drawing on substitutes-for-leadership theory, proposed that followers' proactive personality alleviates the impact of servant leadership on subordinate organizational citizenship behavior (OCB); however, they found that the moderating effect was nonsignificant. In contrast, Newman et al. (2017) found that followers' proactive personality enhanced the positive relationship between servant leadership and followers' OCB. Our findings provide additional support for the amplifying role of proactive personality. The results also contribute to the person-supervisor fit literature by indicating that the combination of employees' proactive personality and servant leadership facilitates employees' job engagement and voice behavior. 
These findings suggest that organizations should develop a servant-oriented management style to facilitate employee voice. Although the impact of servant leadership on employee voice is indirect, occurring through the facilitation of employees' desire for self-enhancement, the findings support the notion that organizational outcomes are the by-products of employees' commitment, trust, and dedication (Timiyo and Yeadon-Lee, 2016). The empirical finding of the positive effect of servant leadership on employee pro-organizational behavior suggests that the implementation of servant leadership is beneficial for organizations. Training and mentoring programs could be provided for managers to instill a service attitude and show them that power can be used to help and care for others. Developing a more humanitarian work culture would also encourage servant leadership (Van Dierendonck, 2011). For example, organizations should emphasize equality and mutual respect between management and staff, and reward employees for being just, friendly, and helpful to others.

The finding regarding the mediating mechanism of job engagement suggests that managers should find ways to increase employees' job engagement to elicit promotive and prohibitive voice behavior. As previously mentioned, Kahn's (1990) three basic psychological prerequisites for engagement (meaningfulness, safety, and availability) can be used to guide managers on how to promote employee job engagement. The resource view suggests that offering employees supplementary workplace resources, such as vision and purpose, teamwork, and development opportunities, can also boost job engagement (Cooper-Thomas et al., 2018).

Our findings regarding the enhancement effect of proactive personality in the servant leadership-voice relationship may have implications for recruitment and staffing. Employees with a high level of proactive personality respond more positively to servant leadership and thus become more engaged with their jobs. Therefore, organizations should match proactive employees with servant leaders to maximize employees' job engagement and voice behavior (Newman et al., 2017). We also advise human resource managers to select people with proactive personalities for departments that rely on employee voice.

\section{Limitations and future directions}

Despite this study's theoretical and practical contributions, some limitations should be noted. First, our theorizing implies that servant leadership has causal effects on employees' job engagement and subsequent voice behavior, but our survey design cannot confirm such causal effects. Although we measured servant leadership, job engagement, and employee voice over time, and in an order that was consistent with the proposed causal effects, these behaviors may have predated our investigation. Therefore, reverse relationships among servant leadership, employees' job engagement, and voice behavior may exist. For example, the results of one cross-sectional survey suggested that voice behavior leads to work engagement (Cheng et al., 2013). It is also possible that servant leadership is shaped by employees' job engagement and voice behavior. Therefore, future studies should consider longitudinal or experimental research designs to confirm causality.

Second, we did not consider the usefulness of employee voice because our survey only used an agreement scale $(1=$ strongly disagree; $5=$ strongly agree $)$ to measure the extent to which employees expressed promotive and prohibitive voice. Therefore, our findings only suggest that servant leadership can encourage employees to express their voice; we were unable to determine whether the ideas and concerns related to employee voice are useful and might be adopted. We recommend that future studies address this issue by measuring the quality of voice, which is important to organizations.

The third limitation arises from the high correlation between servant leadership and transformational leadership, although the discriminant validity of these two constructs exists given that the average variance extracted for servant leadership (0.77) and transformational leadership (0.75) were both higher than the squared correlation (0.72) (Fornell and Larcker, 
1981). In this case, controlling for transformational leadership meant that servant leadership had unique predictive power, as it still exerted significant effects even with the small amount of the variance left. Given the strong predictive power of servant leadership in this study, future research may consider controlling for servant leadership when exploring other leadership style-voice relationships.

\section{Conclusion}

This study empirically tested a moderated mediation mechanism that explains why and when perceived servant leadership influences employees' promotive voice and prohibitive voice based on self-enhancement theory and a person-supervisor fit perspective in a Chinese context. Our research demonstrates that employees can be self-motivated to express both promotive voice and prohibitive voice through increased job engagement, which is in turn facilitated by servant leadership. This is especially applicable to employees who have a high level of proactive personality. These findings provide new insights into the effects of servant leadership and job engagement in Chinese organizations. They also offer practical implications for managers on how to promote employees' voice behavior by displaying servant leadership and enhancing employees' job engagement.

\section{References}

Arain, G.A., Hameed, I. and Crawshaw, J.R. (2019), "Servant leadership and follower voice: the roles of follower felt responsibility for constructive change and avoidance-approach motivation", European Journal of Work and Organizational Psychology, Vol. 28 No. 4, pp. 555-565.

Bateman, T.S. and Crant, J.M. (1993), "The proactive component of organizational behavior: a measure and correlates", Journal of Organizational Behavior, Vol. 14 No. 2, pp. 103-118.

Brislin, R.W. (1980), "Translation and content analysis of oral and written material”, in Triandis, H.C. and Berry, J.W. (Eds), Handbook of Cross-Cultural Psychology, Allyn and Bacon, Boston, Massachusetts, Vol. 2, pp. 349-444.

Brown, S.P. and Leigh, T.W. (1996), "A new look at psychological climate and its relationship to job involvement, effort, and performance”, Journal of Applied Psychology, Vol. 81 No. 4, pp. 358-368.

Chamberlin, M., Newton, D.W. and Lepine, J.A. (2017), “A meta-analysis of voice and its promotive and prohibitive forms: identification of key associations, distinctions, and future research directions", Personnel Psychology, Vol. 70, pp. 11-71.

Chen, Y., Ferris, D.L., Kwan, H.K., Yan, M., Zhou, M. and Hong, Y. (2013), "Self-love's lost labor: a selfenhancement model of workplace incivility", Academy of Management Journal, Vol. 56 No. 4, pp. 1199-1219.

Cheng, J.W., Lu, K.M., Chang, Y.Y. and Johnstone, S. (2013), "Voice behavior and work engagement: the moderating role of supervisor-attributed motives", Asia Pacific Journal of Human Resources, Vol. 51, pp. 81-102.

Christian, M.S., Garza, A.S. and Slaughter, J.E. (2011), "Work engagement: a quantitative review and test of its relations with task and contextual performance", Personnel Psychology, Vol. 64, pp. 89-136.

Cooper-Thomas, H.D., Xu, J. and Saks, A.M. (2018), "The differential value of resources in predicting employee engagement”, Journal of Managerial Psychology, Vol. 33 Nos 4/5, pp. 326-344.

Crant, J.M. (1995), "The proactive personality scale and objective job performance among real estate agents", Journal of Applied Psychology, Vol. 80 No. 4, pp. 532-537.

Crocker, J., Luhtanen, R.K., Cooper, M.L. and Bouvrette, A. (2003), "Contingencies of self-worth in college students: theory and measurement", Journal of Personality and Social Psychology, Vol. 85 No. 5, pp. 894-908.

Duan, J., Kwan, H.K. and Ling, B. (2014), "The role of voice efficacy in the formation of voice behavior: a cross-level examination", Journal of Management and Organization, Vol. 20 No. 4, pp. 526-543. 
Edwards, J.R. and Lambert, L.S. (2007), "Methods for integrating moderation and mediation: a general analytical framework using moderated path analysis", Psychological Methods, Vol. 12 No. 1, pp. 1-22.

Ehrhart, M.G. (2004), "Leadership and procedural justice climate as antecedents of unit-level organizational citizenship behavior", Personnel Psychology, Vol. 57, pp. 61-94.

Ferris, D.L., Lian, H., Brown, D.J. and Morrison, R. (2015), "Ostracism, self-esteem, and job performance: when do we self-verify and when do we self-enhance?", Academy of Management Journal, Vol. 58 No. 1, pp. 279-297.

Fornell, C. and Larcker, D. (1981), "Evaluating structural equation models with unobservable variables and measurement error", Journal of Marketing Research, Vol. 18 No. 1, pp. 39-50.

Gao, A. and Jiang, J. (2019), "Perceived empowering leadership, harmonious passion, and employee voice: the moderating role of job autonomy", Frontiers in Psychology, Vol. 10 No. 1484, pp. 1-9.

Greenleaf, R.K. (1977), Servant Leadership: A Journey into the Nature of Legitimate Power and Greatness, Paulist Press, New York, NY.

Hair, J.F., Black, W.C., Babin, B.J. and Anderson, R.E. (2010), Multivariate Data Analysis, Prentice Hall, Englewood Cliffs, New Jersey.

Hoch, J.E., Bommer, W.H., Dulebohn, J.H. and Wu, D. (2018), "Do ethical, authentic, and servant leadership explain variance above and beyond transformational leadership? A meta-analysis", Journal of Management, Vol. 44 No. 2, pp. 501-529.

Huang, X., Van de Vliert, E. and Van der Vegt, G. (2005), "Breaking the silence culture: stimulation of participation and employee opinion withholding cross-nationally", Management and Organization Review, Vol. 1 No. 3, pp. 459-482.

Kahn, W.A. (1990), "Psychological conditions of personal engagement and disengagement at work", Academy of Management Journal, Vol. 33 No. 4, pp. 692-724.

Kristof-Brown, A.L., Zimmerman, R.D. and Johnson, E.C. (2005), "Consequences of individuals' fit at work: a meta-analysis of person-job, person-organization, person-group, and person-supervisor fit”, Personnel Psychology, Vol. 58 No. 2, pp. 281-342.

Lam, L.W., Huang, X. and Lau, D.C. (2012), "Leadership research in Asia: taking the road less traveled?", Asia Pacific Journal of Management, Vol. 29 No. 2, pp. 195-204.

Liang, J., Farh, C.I. and Farh, J.L. (2012), "Psychological antecedents of promotive and prohibitive voice: a two-wave examination”, Academy of Management Journal, Vol. 55 No. 1, pp. 71-92.

Liden, R.C., Wayne, S.J., Zhao, H. and Henderson, D. (2008), "Servant leadership: development of a multidimensional measure and multi-level assessment", The Leadership Quarterly, Vol. 19 No. 2, pp. 161-177.

Matsunaga, M. (2008), "Item parceling in structural equation modeling: a primer", Communication Methods and Measures, Vol. 2 No. 4, pp. 260-293.

Morrison, E.W. (2011), "Employee voice behavior: integration and directions for future research", The Academy of Management Annals, Vol. 5 No. 1, pp. 373-412.

Muller, D., Judd, C.M. and Yzerbyt, V.Y. (2005), "When moderation is mediated and mediation is moderated", Journal of Personality and Social Psychology, Vol. 89 No. 2, pp. 852-863.

Newman, A., Schwarz, G., Cooper, B. and Sendjaya, S. (2017), "How servant leadership influences organizational citizenship behavior: the roles of LMX, empowerment, and proactive personality", Journal of Business Ethics, Vol. 145, pp. 49-62.

Panaccio, A., Henderson, D.J., Liden, R.C., Wayne, S.J. and Cao, X. (2015), “Toward an understanding of when and why servant leadership accounts for employee extra-role behaviors", Journal of Business and Psychology, Vol. 30 No. 4, pp. 657-675.

Parker, S.K., Williams, H.M. and Turner, N. (2006), "Modeling the antecedents of proactive behavior at work", Journal of Applied Psychology, Vol. 91 No. 3, pp. 636-652. 
JMP

37,1

Pfeffer, J. and Fong, C.T. (2005), "Building organization theory from first principles: the selfenhancement motive and understanding power and influence", Organization Science, Vol. 16 No. 4, pp. 372-388.

Podsakoff, P.M., MacKenzie, S.B., Moorman, R.H. and Fetter, R. (1990), "Transformational leader behaviors and their effects on followers' trust in leader, satisfaction, and organizational citizenship behaviors", The Leadership Quarterly, Vol. 1 No. 2, pp. 107-142.

Rich, B.L., Lepine, J.A. and Crawford, E.R. (2010), "Job engagement: antecedents and effects on job performance", Academy of Management Journal, Vol. 53 No. 3, pp. 617-635.

Saks, A.M. (2006), "Antecedents and consequences of employee engagement”, Journal of Managerial Psychology, Vol. 21 No. 7, pp. 600-619.

Schaufeli, W.B., Salanova, M., González-Romá, V. and Bakker, A.B. (2002), "The measurement of engagement and burnout: a two sample confirmatory factor analytic approach", Journal of Happiness Studies, Vol. 3, pp. 71-92.

Sendjaya, S. and Sarros, J.C. (2002), "Servant leadership: its origin, development, and application in organizations", Journal of Leadership and Organizational Studies, Vol. 9 No. 2, pp. 57-64.

Sonnentag, S. (2003), "Recovery, work engagement, and proactive behavior: a new look at the interface between nonwork and work", Journal of Applied Psychology, Vol. 88 No. 3, pp. 518-528.

Sparks, J.R. and Schenk, J.A. (2001), "Explaining the effects of transformational leadership: an investigation of the effects of higher-order motives in multilevel marketing organizations", Journal of Organizational Behavior, Vol. 22 No. 8, pp. 849-869.

Stone, E.E. and Hollenbeck, J.R. (1989), "Clarifying some controversial issues surrounding statistical procedures for detecting moderator variables: empirical evidence and related matters", Journal of Applied Psychology, Vol. 74 No. 1, pp. 3-10.

Takeuchi, R., Chen, Z. and Cheung, S.Y. (2012), "Applying uncertainty management theory to employee voice behavior: an integrative investigation", Personnel Psychology, Vol. 65 No. 2, pp. 283-323.

Timiyo, A.J. and Yeadon-Lee, A. (2016), "Universality of servant leadership", International Leadership Journal, Vol. 8 No. 3, pp. 3-22.

Van Dierendonck, D. (2011), "Servant leadership: a review and synthesis", Journal of Management, Vol. 37 No. 4, pp. 1228-1261.

Wei, X., Zhang, Z.X. and Chen, X.P. (2015), "I will speak up if my voice is socially desirable: a moderated mediating process of promotive versus prohibitive voice", Journal of Applied Psychology, Vol. 100 No. 5, pp. 1641-1652.

Yan, A. and Xiao, Y. (2016), "Servant leadership and employee voice behavior: a cross-level investigation in China", SpringerPlus, Vol. 5 No. 1595, pp. 1-11.

\begin{abstract}
About the authors
Yang Song (Master's Degree, University of Birmingham) is a $\mathrm{PhD}$ candidate in the College of Business at the Shanghai University of Finance and Economics. Her research interests include leadership and deviant behaviors.

Qi-tao Tian (PhD, Shanghai University of Finance and Economics) is an Associate Professor in the School of Business Administration at the Henan University of Economics and Law. His research interests include job crafting, deviant behaviors and work-family interfaces.

Ho Kwong Kwan (PhD, Drexel University) is an Associate Professor of Management at China Europe International Business School (CEIBS). His research interests include mentoring, leadership, deviant behaviors, and work-family interfaces. Ho Kwong Kwan is the corresponding author and can be contacted at: weicheong2317@hotmail.com
\end{abstract}

For instructions on how to order reprints of this article, please visit our website:

www.emeraldgrouppublishing.com/licensing/reprints.htm

Or contact us for further details: permissions@emeraldinsight.com 